\title{
Study on the Reliability and the Validity for the Sentence-in-Noise Scores at the Fixed Signal-to-Noise Ratios
}

\author{
Na Kyung Kim ${ }^{1,2}$, Dongwoon Yi ${ }^{2}$ Junghwa Bahng ${ }^{2}$, Jae Hee Lee \\ ${ }^{1}$ Keumgang Hearing Aids Center of Ansan, Ansan, Korea \\ ${ }^{2}$ Department of Audiology, Hallym University of Graduate Studies, Seoul, Korea
}

\author{
고정된 신호대잡음비에서의 소음 하 문장인지도의 신뢰도와 타당도에 관한 연구

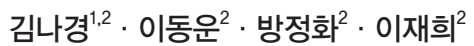 \\ 금강보청기 안산센터 ${ }^{1}$, 한림국제대학원대학교 청각학과 ${ }^{2}$
}

\begin{abstract}
Purpose: Speech understanding in the background noise is one of the common complaints of listeners with hearing loss. Since the routine speech audiometry conducted in quiet usually does not provide sufficient information about a listener's everyday communication ability, the importance of sentence-in-noise recognition tests has been emphasized. Given a limited adaptive sentence-in-noise test in Korea, the ability of sentence-in-noise recognition has been evaluated at a fixed signal-to-noise ratio (SNR). For the efficient and reliable diagnosis using the Korean Matrix Sentences, it is necessary to analyze the reliability and the validity of the materials. The purpose of this study was to investigate test-retest reliability and concurrent validity of the sentence-in-noise recognition scores at fixed SNRs. Methods: Fourteen subjects with bilaterally symmetrical sensorineural hearing loss participated. All the listeners have used bilateral hearing aids, and their aided puretone threshold average was $38 \mathrm{~dB} \mathrm{HL}$. The materials of the Korean Standard Sentence Lists for Adults (KS-SL-A) and the Korean Matrix sentences were presented at 80 dB SPL through loudspeakers while wearing listener's hearing aids. Listeners' sentence recognition score was measured in quiet and three noise conditions (6, 3, $0 \mathrm{~dB}$ SNRs) at 10-week interval. The Korean Hearing in Noise Test was also administered for the purpose of validity test. Results: The results exhibited the strong test-retest reliability for each material, regardless of listening conditions (quiet, 6, 3, $0 \mathrm{~dB}$ SNR). The concurrent validity of each material was also determined between results of the KS-SL-A and the Korean Matrix sentences. However, some subjects could not recognize sentences in noise for the KS-SL-A and the K-HINT tests, indicating difficulty in adjusting test level. Conclusion: When evaluated at the fixed SNRs, the sentence-in-noise scores of the Korean Matrix sentences showed a good test-retest reliability test-retest reliability and concurrent validity. More studies are needed to determine the reliability and the validity for the materials of adaptive sentence-in-noise tests.
\end{abstract}

Key Words: Sentence-in-noise recognition, Speech audiometry, Signal-to-noise ratio, Sentence recognition score.

\section{INTRODUCTION}

현대인들은 다양한 소음 속에서 일상생활을 하고 있으며 난 청인은 물론 정상 청력을 가진 청자 또한 소음 속에서 어음을 인지할 때 어려움을 갖는다. 난청인의 어음인지 능력을 측정하 기 위해 임상에서는 대부분 조용한 상황에서 일음절 단어를 제시하고 인지도를 측정하고 있다. 이를 통해 청자의 단어인지 능력을 객관적으로 분석하고 단어 내 음소 오류를 파악하는 데
유리한 장점이 있다. 그러나 단어만을 제시하고 인지도를 측정 할 경우 청자의 일상생활 속 의사소통 능력을 예측하기에는 한 계가 있다. 이러한 한계점을 극복하기 위해 고정된 신호대잡음 비(signal-to-noise ratio, SNR)에서 혹은 SNR을 조절해 가며 소음 하 문장인지도를 측정할 수 있다.

국외에서는 다양한 소음 하 문장인지 검사 도구를 개발 및 표준화하여 임상에서 적극적으로 사용하고 있다. 신호대잡음비 를 고정시킨 채 검사를 시행하는 고정형 소음 하 문장인지 검 
사 도구로는 Speech Perception in Noise Test (Kalikow et al., 1977), City University of New York Test (Boothroyd et al., 1985), Connected Speech Test (Cox et al., 1987) 등이 있고, 대상자의 반응에 따라 SNR을 조절하는 변동형 검사 도구로는 Hearing in Noise Test (Nilsson et al., 1994), Quick Speechin-Noise Test (Killion et al., 2004), Matrix Sentence Test (Akeroyd et al., 2015) 등이 있다. 고정형 소음 하 문장인지 검사의 경우 결과를 백분율로 점수화하므로 대상자가 검사 결과를 이 해하기 더 쉽다는 장점이 있고, 변동형 검사 도구는 기존의 검 사 도구에 비해 검사 소요시간이 짧고 검사의 난이도를 조절하 기 쉬우며 결과 판독에 있어 유리하다.

국내의 경우 표준화된 변동형 소음 하 문장인지 검사 도구의 개발이 많이 이루어지지 않았다. 과거 2008년에 발표된 Korean Hearing in Noise Test (K-HINT)는 미국의 House Ear Institute와 결연하여 개발한 변동형 검사 도구로 표준화 작업 이 일부 진행되었다(Moon et al., 2008). 그러나 K-HINT는 일 반적인 컴퓨터가 아닌 HINT pro (Bio-logic ${ }^{\circledR}$ Systems Corp., Mundelein, IL, USA)라는 장비를 통해서만 검사가 가능하여 검사의 접근성이 떨어진다는 단점이 있다. 한국표준 일반용 문 장표(Korean Standard Sentence Lists for Adults, KS-SL-A) (Jang et al., 2008)의 경우 조용한 듣기 상황에서 평가하도록 개발되었으나 소음 하에서 문장인지 검사를 시행하기도 한다. 그 외 한국어 행렬문장(Korean Matrix sentence, Yi, 2016, 이 하 한국어 Matrix 문장이라 함)을 이용하여 소음 하 문장인지 도를 측정할 수 있다. 이 두 가지 도구 모두 변동형 도구로 개발 하지 않았으므로 변동형 검사를 위한 소프트웨어 개발되기 전 까지는 고정된 SNR에서 검사를 진행해야 한다. 또한 정상 청력 성인에 대한 분석은 진행되었으나 난청인을 대상으로 소음 하 검사 결과의 신뢰도 및 타당도에 대한 연구 보고가 부재하다.

보통 신뢰도 검증을 위해서는 검사-재검사 신뢰도, 동형검사 신뢰도, 반문 신뢰도, 문항 내적 일치 정도 등의 다양한 방법을 활용할 수 있다. 난청인을 대상으로 하는 청각검사의 경우 재활 기간 동안 여러 번 동일 검사를 시행하게 되기 때문에 검사를 반복적으로 시행하였을 때 얼마나 결과가 일치하는지 확인하 는 검사-재검사 신뢰도의 검증이 중요하다. 본 연구에서는 한 국어 Matrix 문장을 임상에서 사용하기 위한 검증 작업의 일 부로 고정된 SNR에서 두 가지 문장 목록(KS-SL-A, 한국어 Matrix)을 제시하여 검사-재검사 신뢰도(test-retest reliability) 와 공인 타당도(concurrent validity)를 확인하고자 하였다. 난 청인을 대상으로 검사-재검사 신뢰도 확인을 위해 소음을 제 시하지 않은 상황(quiet)과 $6,3,0 \mathrm{~dB} \mathrm{SNR}$ 의 소음 상황에서 10 주 간격으로 2 회의 검사를 시행하여 결과의 신뢰도를 검증 하였다. 공인 타당도를 확인하고자 KS-SL-A와 한국어 Matrix
문장인지 결과 간 상관성, 기존의 변동형 HINT 결과와의 상관 성을 분석하였다.

\section{MATERIALS AND METHODS}

\section{연구 대상}

본 연구에는 총 14 명의 난청 성인이 참여하였다(평균 연령 53 세, 연령 범위 31 81세, 남 7, 여 7). 대상자 4명을 제외하고는 모 두 60세 미만이었으며, 대상자 모두 어지럼, 이명, 신경학적 병 력을 가지지 않았고 양이 대칭형 감각신경성 난청을 가지고 있 었다. 순음청력검사기(GSI 61; Grason-Stadler, Eden Prairie, $\mathrm{MN}, \mathrm{USA}$ )로 측정한 250 8,000 Hz 이내 옥타브 단위 주파수 별 순음청력역치를 살펴보면, 오른쪽 귀의 경우 $57,57,58,58$, $64,68 \mathrm{~dB}$ HL이었고 왼쪽 귀의 경우 $54,58,59,59,64,69 \mathrm{~dB}$ $\mathrm{HL}$ 이었다. 오른쪽 귀의 $500,1,000,2,000 \mathrm{~Hz}$ 주파수의 평균 순음역치(puretone threshold average, PTA)는 $58 \mathrm{~dB} \mathrm{HL}$, 왼 쪽 귀의 경우 $59 \mathrm{~dB}$ HL이었다. 대상자 모두 양이에 보청기를 사용 중이었다. 양이 보청기를 착용하고 $250 \sim 4,000 \mathrm{~Hz}$ 이내 옥 타브 단위의 주파수에서 측정한 순음청력역치는 $37,37,37,39$, $47 \mathrm{~dB} \mathrm{HL}$ 이었고, $500,1,000,2,000 \mathrm{~Hz}$ 주파수의 PTA는 평균 $38 \mathrm{~dB} \mathrm{HL}$ (범위: 27 48 dB HL, 표준편차: 6)이었다.

14 명의 대상자 중 60 세 이상의 4 명의 대상자에게 치매선별 검 사인 mini-mental state examination Korean version (Kwon $\&$ Park, 1989)을 시행한 결과, 노년 대상자 모두 정상 인지기능 을 가졌음을 확인하였다. 문장인지 능력을 측정할 때 작업기억 능력의 저하로 저하된 인지도를 보일 수 있으므로 유사한 범위 의 능력을 보이는지 알아보는 것이 필요하다. 따라서 대상자 모 두에게 순방향 숫자기억능력(forward digit span), 역방향 숫자 기억능력(backward digit span)을 측정하여 작업기억능력을 평 가하였다. 측정 결과 대상자의 평균 순방향 숫자기억능력은 6.3(범위: 5 7, 표준편차: 0.7), 평균 역방향 숫자기억능력은 3.5 (범위: $3 \sim 5$, 표준편차: 0.7)이었다. 본 연구에 참여한 대상자 모두 대상자 모두 연구 참여 전 연구의 목적 및 절차에 대한 설 명을 듣고 연구 참여에 동의하였다(IRB \#: HUGSAUD57 8164).

\section{연구 절차}

본 연구의 실험은 스피커를 통해 $80 \mathrm{~dB}$ SPL에서 KS-SL-A (Jang et al., 2008)와 한국어 Matrix 문장(Yi, 2016)을 제시하 였다. 검사 시 보기 없이 각 문장을 제시하고 문장 내 단어를 따라 말하게 하여 검사를 진행하였다. 실험은 총 네 가지 듣기 조건[배경 소음을 제시하지 않은 조용한 상황(quiet)과 $6,3,0$ $\mathrm{dB} \mathrm{SNR}$ 의 세 가지 소음 하 조건]에서 시행하여 문장인지도를 측정하였다. Adobe Audition CC 2015 (Adobe Systems Inc., 
San Jose, CA, USA)를 이용하여 각 문장의 실효값(root mea square)이 동일하도록 $( \pm 1 \mathrm{~dB})$ 조절하였고, 한국어 어음스펙트 럼을 가진 비유동성(stationary) 소음(Yi, 2016)을 배경 소음으 로 사용하여 $6,3,0 \mathrm{~dB} \mathrm{SNR}$ 의 음원을 제작하였다.

$\mathrm{KS}-\mathrm{SL}-\mathrm{A}$ 는 일반 성인, 학령기 아동, 학령전기 아동을 대상 으로 개발한 목록 중 일반 성인용 문장 목록에 해당한다(Jang et al., 2008). KS-SL-A 문장인지도 채점을 위해 개발자가 제 시한 중심 단어(keyword)를 기준으로(목록당 40개 중심단어) 백분율로 결과를 계산하였다. 한국어 Matrix 문장의 경우 모 든 문장에 5 개의 단어가 포함되어 있으므로 5 개 단어를 기준 으로 점수화(\%)하였다. KS-SL-A (Jang et al., 2008)와 한국어 Matrix 문장 검사 외에 변동형 검사 도구인 $\mathrm{K}-\mathrm{HINT}$ 를 함께 진행하였다. K-HINT는 위의 검사 도구처럼 백분율(\%)로 결과 를 산출하지 않고 $50 \%$ 인지에 필요한 SNR을 확인하여 소음 하 인지능력을 평가하는 변동형 검사 도구이다. 검사를 위해 $65 \mathrm{dBA}$ 고정된 강도에서 어음스펙트럼 소음을 제시하고 목표 문장을 $50 \%$ 옳게 인지하는 데 필요한 SNR을 찾기 위해 목표 문장의 강도를 증가시키거나 감소시키므로, $65 \mathrm{dBA}$ 의 소음 속 에서 문장을 인지하는 것이 불가능한 경우 검사를 진행하기 어 렵다는 단점이 있다. 따라서 $\mathrm{K}-\mathrm{HINT}$ 의 경우 검사 참여가 가 능한 난청인만을 대상으로 이를 진행하였다.

동일한 평가를 반복할 경우 학습 효과 등의 영향이 주어질 수 있어 1 2일 간격이 아닌 최소 3개월 이상의 간격을 두고 동 일한 검사를 시행하여야 한다. 따라서 본 각 듣기 조건에서 10 주, 약 3 개월 간격으로 2 회의 검사를 시행하였으며, 검사 시 대상자 가 선호하는 보청기 적합 상태를 유지하며 양이 보청기를 착용 한 채 실험에 참여하였다. 검사소요시간은 약 40 50분이었다.

\section{통계 분석}

측정 결과는 SPSS version 20.0 (IBM Corp., Armonk, NY, USA) 소프트웨어를 이용하여 분석하였다. 본 연구에서는 6,3 , $0 \mathrm{~dB} \mathrm{SNR}$ 의 듣기 조건에서 측정한 문장인지도 결과를 종속변 수로 하여 대응표본 $t$ 검정을 시행하였고, Pearson 상관 분석 을 통해 검사-재검사 결과 간 상관계수를 산출하여 검사-재검 사 신뢰도를 분석하였다. 여러 검사 결과 간 Pearson 상관성 분 석을 시행하고 상관계수를 산출하여 공인 타당도를 검증하였 다. 모든 통계분석은 유의수준 0.05 를 기준으로 하였다.

\section{RESULTS}

\section{신뢰도 검증을 위한 검사-재검사 결과 분석}

Figure 1은 KS-SL-A 문장을 제시하였을 때의 검사-재검사 평균 문장인지도를, Figure 2는 검사-재검사 시 측정한 개인별
문장인지도를 산점도(scatterplot)로 나타내었다. 소음을 제시 하지 않은 상황과 $6,3,0 \mathrm{~dB} \mathrm{SNR}$ 듣기 조건별로 살펴보면, 첫 번째 검사 시 평균 문장인지도는 $90,64,57,49 \%$ (표준편차: $7.6,22.5,20.5,23), 10$ 주 후 재검사 시 평균 문장인지도는 92 , $68,63,52 \%$ (표준편차: $8.4,21,22.5,18.6$ )였다. 조용한 상황과 소음 조건에서의 문장인지도 결과를 비교하면 조용한 상황에 비해 소음 조건에서 문장인지도가 저하되었을 뿐 아니라 개인 간 표준편차도 증가하였음을 알 수 있다. Figure 2에 나타내었 듯이, 14 명의 대상자 중 1 명은 $3 \mathrm{~dB} \mathrm{SNR}$ 에서 검사를 시행할 수 없었고 4명은 $0 \mathrm{~dB} \mathrm{SNR}$ 에서 검사를 시행할 수 없었다.

검사-재검사 결과 간 차이를 확인하기 위해 대응표본 $t$ 검정 을 시행한 결과 모든 듣기 조건에서 유의한 차이를 보이지 않았 다 $(p>0.05)$. Pearson 상관분석 결과 모든 듣기 조건에서의 검 사-재검사 결과 간 유의한 상관성을 보였다 $(0.66<r<0.90$, $p<0.05)$. 따라서 $\mathrm{KS}-\mathrm{SL}-\mathrm{A}$ 문장을 이용하여 10 주의 간격을

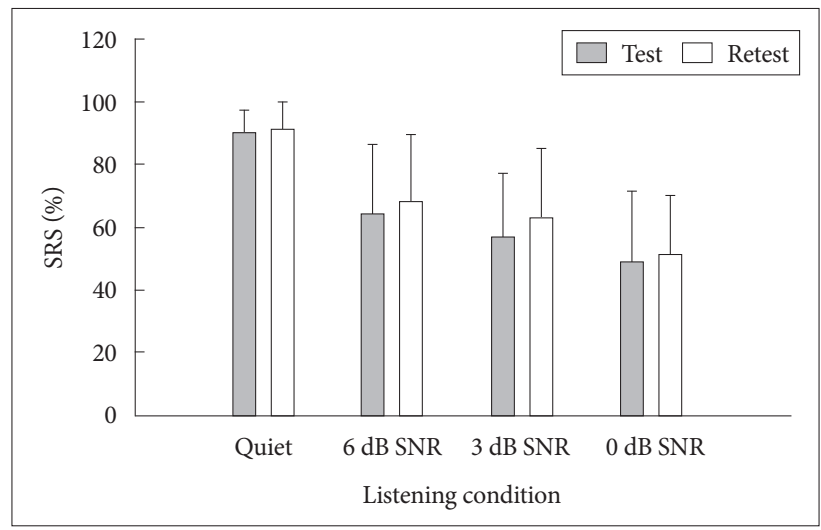

Figure 1. Test-retest mean SRS (\%) of the KS-SL-A when evaluated in quiet and at 6, 3, $0 \mathrm{~dB}$ SNRs. SRS: sentence recognition score, SNR: signal-to-noise ratio, KS-SL-A: Korean Standard Sentence Lists for Adults.

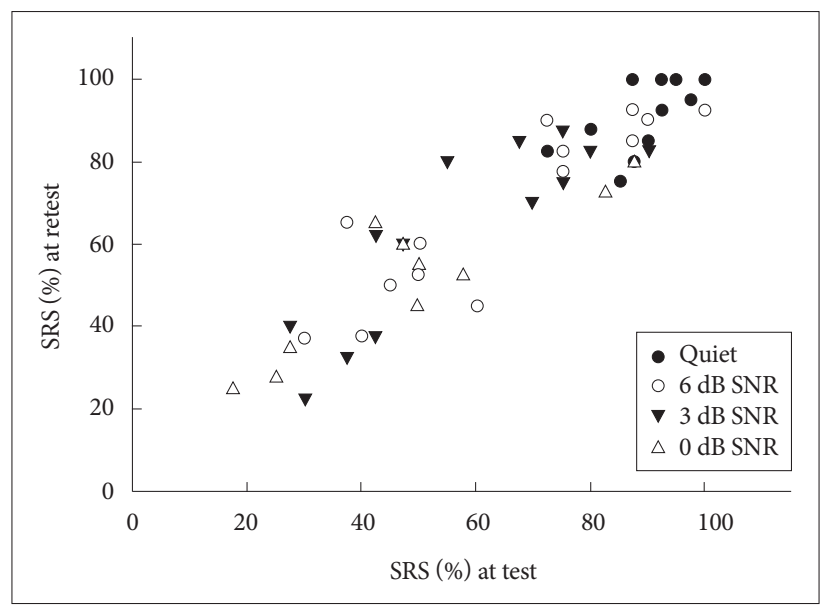

Figure 2. Scatterplot between test-retest mean SRS (\%) of the KSSL-A when evaluated in quiet and at $6,3,0 \mathrm{~dB}$ SNRs. SRS: sentence recognition score, SNR: signal-to-noise ratio, KS-SL-A: Korean Standard Sentence Lists for Adults. 
두고 검사를 2회 반복 시행하였을 때 $\mathrm{KS}-\mathrm{SL}-\mathrm{A}$ 문장인지 결과 가 유의하게 다르지 않고 상관 계수도 높아 검사-재검사 결과 의 신뢰도가 적절함을 확인하였다.

Figure 3은 한국어 Matrix 문장을 제시하고 측정한 검사-재 검사 평균 문장인지도를 보여주며, Figure 4는 개인별 검사-재 검사 결과를 산점도로 나타낸다. Figure 3에 제시하였듯이 첫 번째 검사에서 소음을 제시하지 않은 조건과 $6,3,0 \mathrm{~dB} \mathrm{SNR}$ 조건에서 측정한 평균 문장인지도는 $78,76,71,62 \%$ (표준편차: 17.1, 19.2, 21.3, 24.6)였고, 10 주 후 재검사 시 평균 문장인지도 는 $83,75,71,62 \%$ 였다(표준편차: $15.3,18.5,18.7,23.5$ ). 조용한 상황에서 $\mathrm{KSA}$ 문장을 제시하였을 때 평균 문장인지도가 $90 \%$ 이상이었던 것에 비해 Matrix 문장을 제시한 경우 평균 인지도 가 다소 감소하였으며, 대부분의 소음 조건에서 개인 간 편차가 컸다. Figure 4에 나타내었듯이, 한국어 Matrix 문장을 제시한 경우 14 명의 대상자 모두 $6,3,0 \mathrm{~dB} \mathrm{SNR}$ 듣기 조건에서 검사 를 시행할 수 있었다.

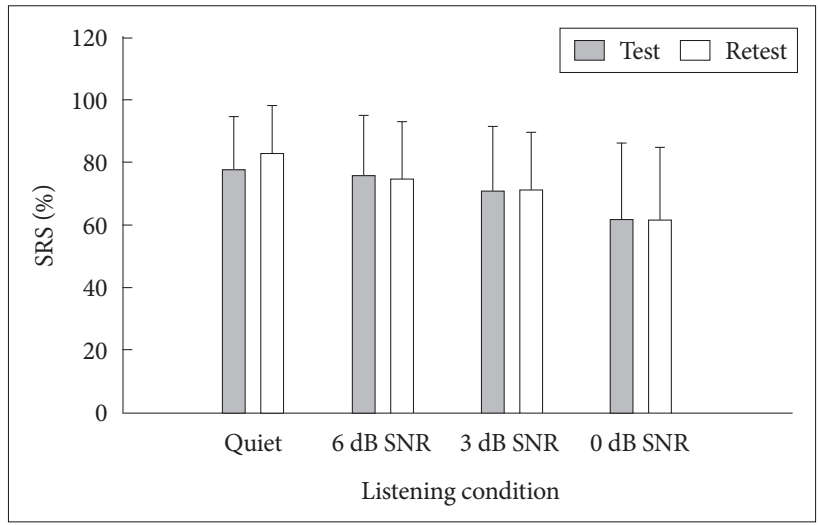

Figure 3. Test-retest mean SRS (\%) of the Korean Matrix when evaluated in quiet and at $6,3,0 \mathrm{~dB}$ SNRs. SRS: sentence recognition score, SNR: signal-to-noise ratio.

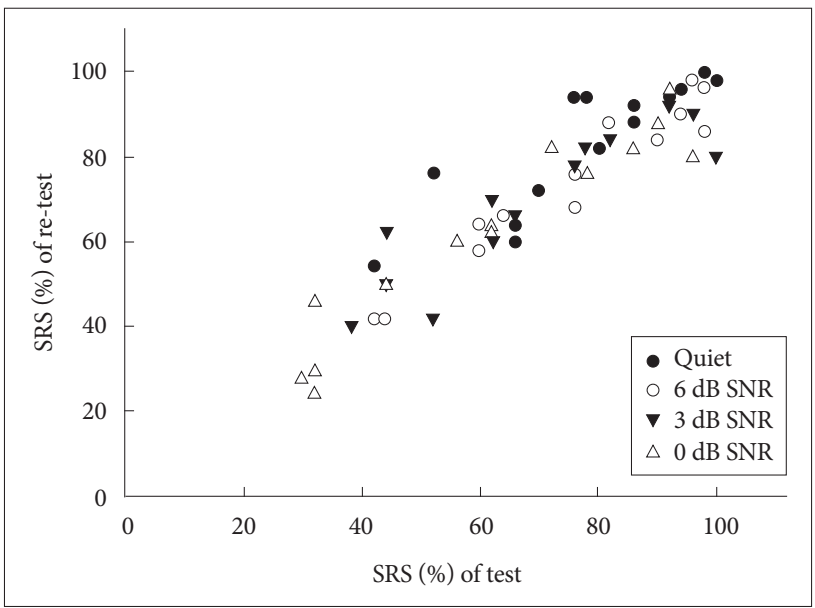

Figure 4. Scatterplot between test-retest mean SRS (\%) of the Korean Matrix when evaluated in quiet and at 6, 3, $0 \mathrm{~dB}$ SNRs. SRS: sentence recognition score, SNR: signal-to-noise ratio.
대응표본 $t$ 검정 결과 모든 듣기 조건에서 인지도가 유의하게 다르지 않았다 $(p>0.05)$. Pearson 상관분석을 시행한 결과 모 든 듣기 조건에서의 검사-재검사 결과 간 상관 계수 r이 0.86 0.96으로 높은 상관성을 보였다. 즉, 10 주의 간격을 두고 검사 를 2회 반복 시행하였을 때 고정된 SNR에서 측정한 Matrix 문 장인지 결과가 유의하게 다르지 않고 상관 계수도 높아 검사재검사 신뢰도가 우수함을 확인하였다.

\section{공인 타당도 검증을 위한 상관성 분석}

한국어 Matrix 문장인지도 결과가 기존의 $\mathrm{KS}-\mathrm{SL}-\mathrm{A}, \mathrm{K}-$ HINT 결과와 비교하였을 때 얼마나 공통된 요인을 지니는지, 소음 상황에서의 의사소통 어려움을 잘 측정하고 있는지 등을 판단하는 공인 타당도를 알아보고자 하였다. 이를 위해 본 연 구에서는 고정된 SNR 듣기 조건(6, 3, $0 \mathrm{~dB} \mathrm{SNR}$ 과 조용한 상 황에서 $\mathrm{KS}-\mathrm{SL}-\mathrm{A}$ 와 한국어 Matrix 문장인지도(\%)를 평가하였 고, $\mathrm{K}-\mathrm{HINT}$ 를 통해 $50 \%$ 인지를 보이는 문장인지역치(dB SNR) 를 측정하였다.

대상자별 문장인지도 간 상관성을 알아보기 위해 산점도를 그려 Figure 5, 6에 제시하였다. 앞서 기술하였듯이, 한국어 Matrix 문장 제시 시 14명의 대상자 모두 인지도 측정이 가능하 였고, KS-SL-A 문장을 사용한 경우 14명 중 10명만 $0 \mathrm{~dB} \mathrm{SNR}$ 에서 문장을 인지하는 것이 가능하였다. K-HINT 측정의 경우 14 명 중 8 명만 참여가 가능하였으므로 이에 해당하는 결과를 Figure 5, 6에 나타내었다.

Figure 5는 첫 번째 검사에서 측정한 결과이다. Figure $5 \mathrm{~A}$ 는 각 듣기 조건에서 $\mathrm{KS}-\mathrm{SL}-\mathrm{A}$, 한국어 Matrix 문장인지도 간 상 관성을 보여주는 그림이며, Figure $5 \mathrm{~B}$ 는 KS-SL-A와 K-HINT 간 상관성을, Figure $5 \mathrm{C}$ 는 한국어 Matrix 문장인지도와 $\mathrm{K}-$ HINT 결과 간 상관성을 보여준다. Pearson 상관분석 결과 $\mathrm{KS}-$ $\mathrm{SL}-\mathrm{A}$ 와 한국어 Matrix 문장을 이용한 결과 간 상관성은 모든 소음 하 듣기 조건에서 유의하였으나 $(\mathrm{r}=0.83, p<0.05)$ 조용한 상황에서의 인지도 결과 간 유의한 상관성은 없었다. KS-SL-A 와 K-HINT 결과 간 관련성을 확인한 결과, $3 \mathrm{~dB} \mathrm{SNR을} \mathrm{제외}$ 한 모든 조건에서 측정한 $\mathrm{KS}-\mathrm{SL}-\mathrm{A}$ 문장인지도와 $\mathrm{K}-\mathrm{HINT}$ 결 과 간 유의한 관련성을 보였다 $(-0.86<\mathrm{r}<-0.82, p<0.05)$. 또한 모든 조건에서 측정한 한국어 Matrix 문장인지도와 $\mathrm{K}-$ HINT 결과 간 상관성 역시 유의하였다 $(-0.85<\mathrm{r}<-0.73, p<$ 0.05).

Figure 6 은 10 주 후 재검사 시 측정한 결과이다. Figure $6 \mathrm{~A}$ 는 각 조건에서 측정한 $\mathrm{KS}-\mathrm{SL}-\mathrm{A}$ 와 한국어 Matrix 문장인지 도 간 상관성을 보여주며, Figure $6 \mathrm{~B}, \mathrm{C}$ 는 KS-SL-A 결과와 KHINT 결과, 한국어 Matrix 결과와 K-HINT 결과 간 상관성을 보여준다. KS-SL-A 결과와 한국어 Matrix 문장인지도 간 상 

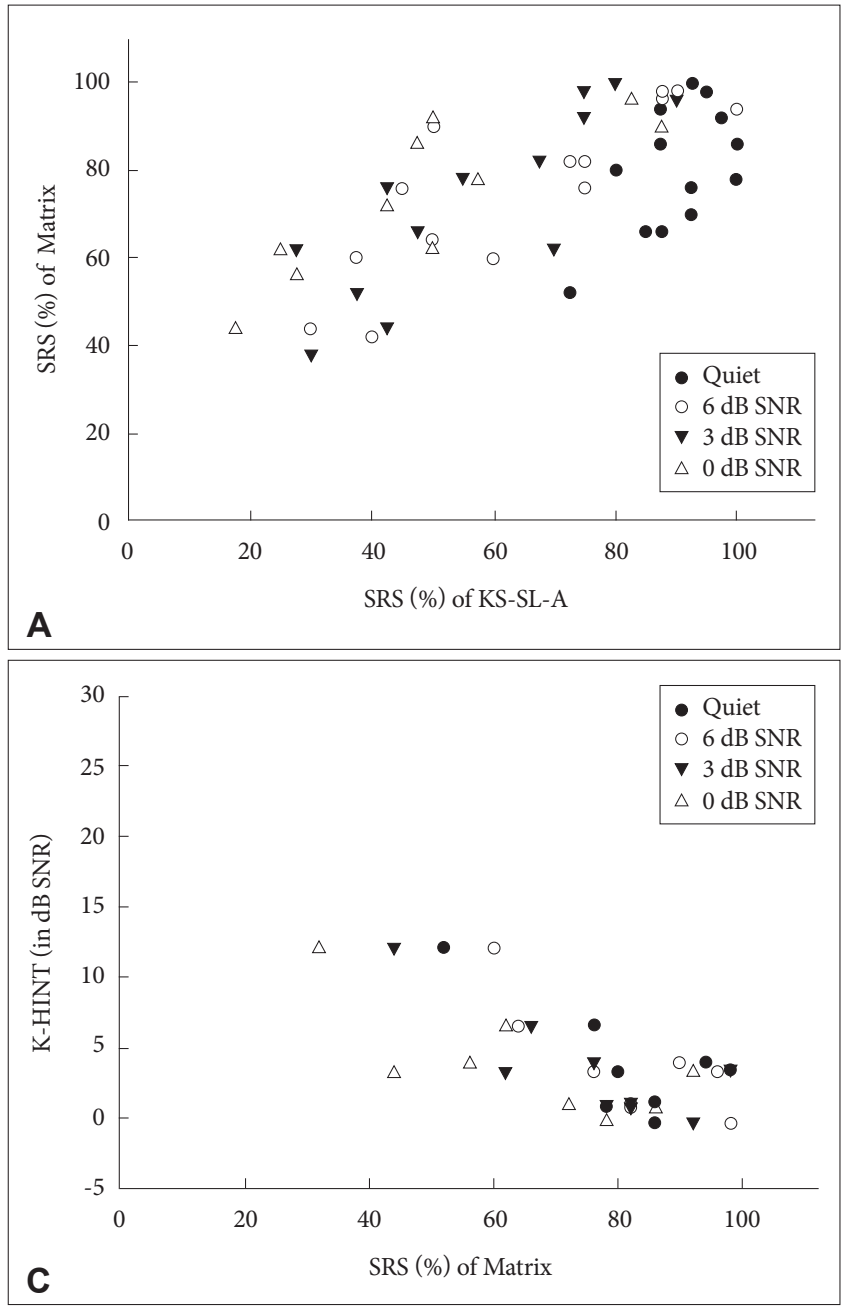

관성은 모든 조건에서 유의하였으며 상관 계수도 높게 나타났 다 $(\mathrm{r}=0.81 \sim 0.89, p<0.05)$. 한국어 Matrix 문장을 이용하여 측정한 소음 하 문장인지도 중 $6 \mathrm{~dB} \mathrm{SNR}$ 과 $3 \mathrm{~dB} \mathrm{SNR}$ 조건에 서 두 결과 간 유의한 상관성을 보였다 $(-0.81<\mathrm{r}<-0.71, p<$ 0.05). KS-SL-A 소음 하 문장인지도와 $\mathrm{K}-\mathrm{HINT}$ 결과 간 관련성 은 유의하지 않았다 $(p>0.05)$.

\section{DISCUSSIONS}

현재 임상에서 난청인의 의사소통 능력을 측정하기 위해서 단어인지도(word recognition score)를 측정하고 있으며 경우 에 따라서 문장인지도(sentence recognition score) 검사를 시 행하고 있다. 이러한 검사 방법은 모두 소음을 제시하지 않은 조용한 상황에서 시행하는 것이므로 난청인의 일상적인 소음 하 의사소통 능력을 파악하기는 어렵다. 소음 하에서의 어려움 을 객관적으로 평가하기 위해 소음 하 어음청각검사 도구의 개 발이 필요하며, 임상에서 도구를 사용하기 위해 결과의 신뢰도

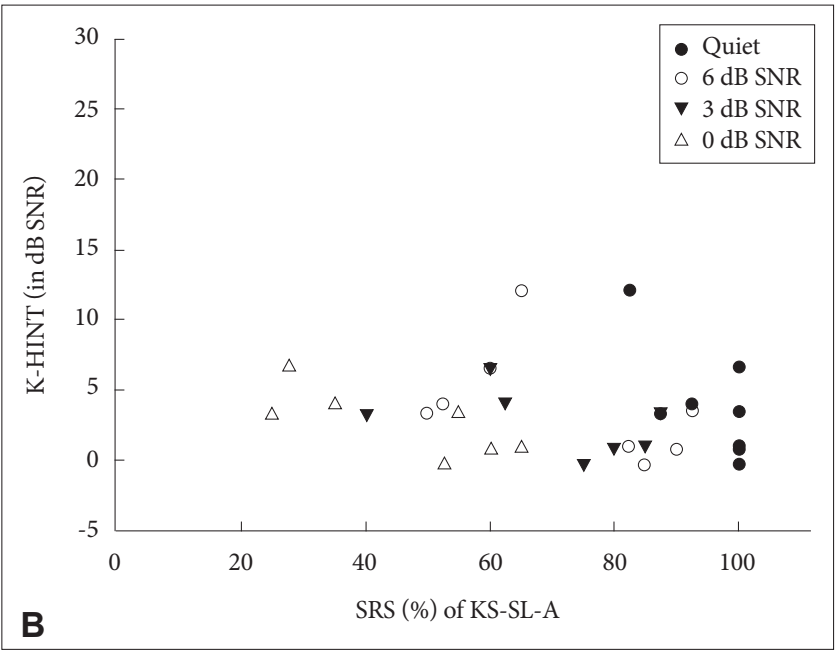

Figure 5. Scatterplots (test 1) among results of the KS-SL-A, the Korean Matrix, the K-HINT tests (A: Scatterplot between results of the KS-SL-A and the Korean Matrix. B: Scatterplot between results of the KS-SL-A and the K-HINT. C: Scatterplot between results of the Korean Matrix and the K-HINT). The KS-SL-A and the Korean Matrix tests were evaluated in quiet and at 6, 3, 0 dB SNRs. KS-SL-A: Korean Standard Sentence Lists for Adults, K-HINT: Korean Hearing in Noise Test.

와 타당도를 확인하는 등의 과정이 필요하다. 따라서 본 연구에 서는 한국어 Matrix 문장을 임상에서 사용하기 위한 검증 작업 의 일부로 난청인에게 고정된 SNR에서 $\mathrm{KS}-\mathrm{SL}-\mathrm{A}$ 와 한국어 Matrix 문장을 제시하여 검사-재검사 신뢰도와 공인 타당도를 확인하였다.

먼저 본 연구의 난청인 신뢰도 검증 결과를 살펴보면 10주의 간격을 두고 재검사를 반복 시행하였음에도 불구하고 모든 조 건에서의 $\mathrm{KS}-\mathrm{SL}-\mathrm{A}$ 와 Matrix 문장인지도 검사 결과에 유의한 차이가 없고 상관성을 보여 고정된 SNR에서 한국어 Matrix 문 장을 제시하였을 때 결과의 검사-재검사 신뢰도가 적절하다고 볼 수 있다. 본 연구와 유사하게 국외 연구에서도 검사 도구의 검사-재검사 신뢰도가 부족한 경우 후속 연구로서 이를 검증한 바 있다(Cokely \& Humes, 1992; Siegenthaler, 1975; Winkler \& Holube, 2016). 예를 들어 Cockely \& Humes(1992)는 기존 의 소음 하 검사 도구인 Speech Perception in Noise (SPIN) (Kalikow et al., 1977), Dichotic Sentence Identification (DSI) (Fifer et al., 1983)이 건청인을 대상으로만 검증되었다는 것을 

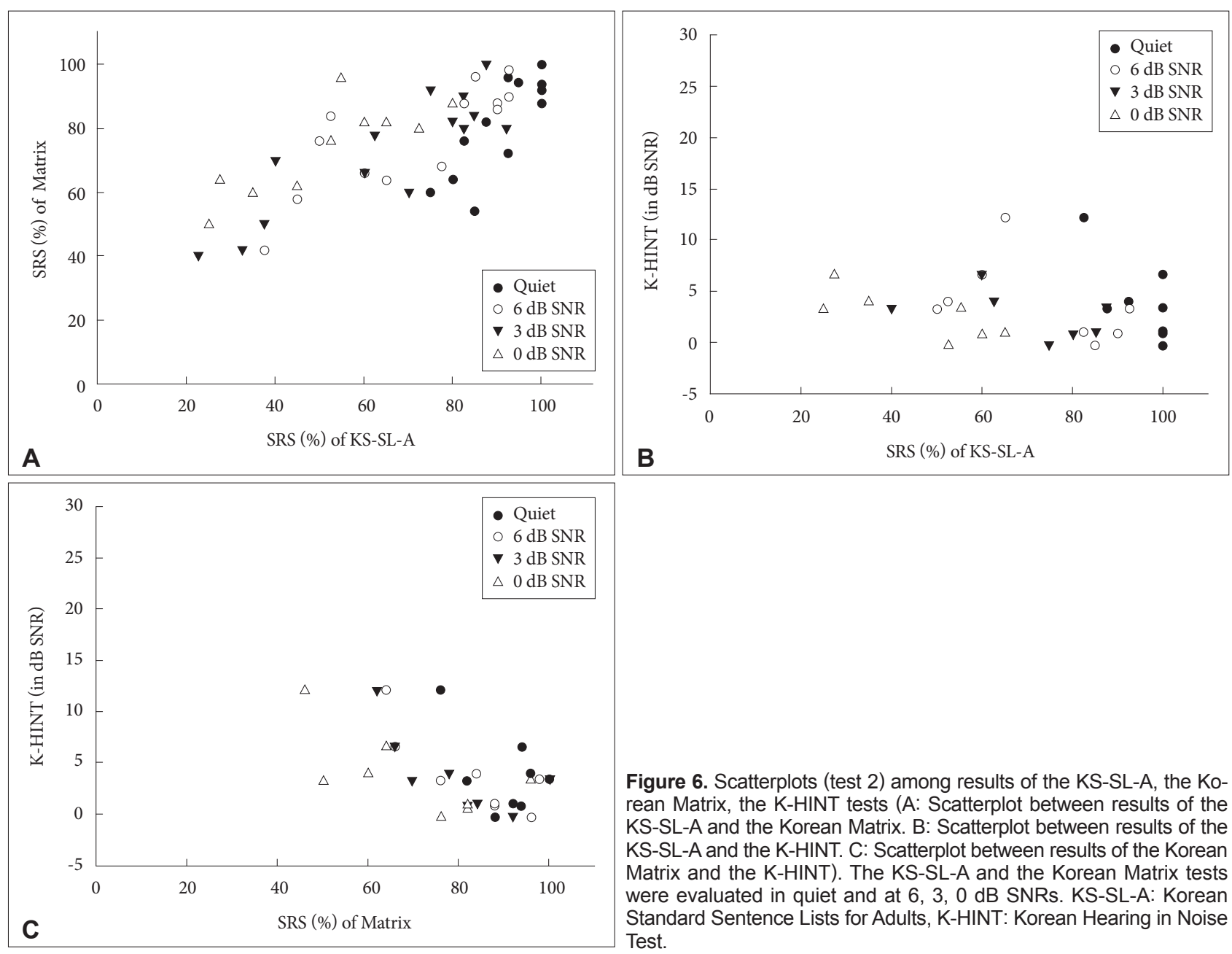

Figure 6. Scatterplots (test 2) among results of the KS-SL-A, the Korean Matrix, the K-HINT tests (A: Scatterplot between results of the KS-SL-A and the Korean Matrix. B: Scatterplot between results of the KS-SL-A and the K-HINT. C: Scatterplot between results of the Korean Matrix and the K-HINT). The KS-SL-A and the Korean Matrix tests were evaluated in quiet and at 6, 3, 0 dB SNRs. KS-SL-A: Korean Standard Sentence Lists for Adults, K-HINT: Korean Hearing in Noise Test.

고려하여 난청 노인을 대상으로 검사-재검사 신뢰도를 분석하 였다. 1 2주의 간격을 두고 SPIN과 DSI 문장인지 검사를 3번 반복 평가하여 검사-재검사 신뢰도를 분석하였고 $65,75,85$ $\mathrm{dB}$ SPL에서 각 문장을 제시하였다. 본 연구와 유사하게 고정 된 SNR에서 소음 하 문장인지 검사를 시행한 결과 난청 노인 대상자 간 편차가 컸고 신뢰도가 좋지 않아 위 검사를 시행할 때 주의를 기울일 것을 밝혔다. 따라서 건청인 검증 결과만으로 실제 임상에서 난청인에게 적용 가능한지를 판단하는 데 주의 가 필요함을 알 수 있다.

본 연구에서는 난청인이 보청기를 끼고 충분히 들을 수 있는 레벨인 $80 \mathrm{~dB}$ SPL에서 문장을 제시하였고, 이 레벨을 기준으 로 $6,3,0 \mathrm{~dB} \mathrm{SNR}$ 의 소음 조건에서 문장인지도를 측정하였을 때 난청인 대상자 간 편차가 약 16 24\%로 큼을 확인하였다. 이 와 유사하게 선행 연구에서도 난청인의 가청정도(audibility)가 확보되었는데도 난청인의 문장인지도 결과에서 편차가 컸음을 보고하였다(Bilger et al., 1984; Cockely \& Humes, 1992). Cockely \& Humes(1992)는 DSI 문장을 65, 75, 85 dB SPL에
서 제시한 결과 평균 문장인지도는 $41 \%$ 부터 $68 \%$ 였고 편차가 34 40\%라 보고하였다. Bilger et al.(1984)은 SPIN 문장을 난 청인의 역치보다 $50 \mathrm{~dB}$ 더 큰 레벨인 $50 \mathrm{~dB}$ SL에서 제시한 결 과 편차가 약 25 30\%였다고 보고하였다. 본 연구에서 소음을 제시하지 않은 조용한 상황에서 검사를 시행한 경우 Matrix 문 장을 제시하였을 때보다 $\mathrm{KS}-\mathrm{SL}-\mathrm{A}$ 의 평균 문장인지도가 더 높 았고(90\%) 편차는 비교적 적었다. 그 이유는 KS-SL-A에 포함 된 문장이 미국 The Central Institute for the Deaf (CID) Everyday Sentence test (Silverman \& Hirsh, 1955) 목록에 포함 된 문장 내 어휘 선정 및 문장 구조 면에서 유사한 점(Jang et al., 2008)을 고려해볼 수 있다. KS-SL-A와 CID 문장 목록 모두 2 3개 단어만을 포함하는 문장이 다수 포함되어 있어 조용한 상황에서 난청인이 인지하기에 큰 어려움을 가지지 않았을 것 으로 추정된다.

대부분의 선행 연구에서 기존 검사 도구의 검사-재검사 신 뢰도를 주로 건청인을 대상으로 보고한 것을 고려하여 본 연구 에서는 난청인을 대상으로 검사-재검사 신뢰도를 확인하였고, 
그 외에 타당도를 확인하여 검사에서 실제로 확인하고자 하는 사항을 잘 측정하고 있는지를 알아보았다. 검사 도구의 타당도 를 검증하기 위해 여러 가지 방법을 활용할 수 있는데, 본 연구 에서는 새로 개발된 검사 결과가 기존의 다른 검사 결과와 공 통된 요인을 가지는지 판단하기 위해 공인 타당도를 검증하였 다. 이를 위해 약 3 개월의 간격을 두고 2회의 검사를 실시한 결 과 모든 소음 하 결과에서 한국어 Matrix 문장인지 결과가 소 음 하 KS-SL-A, K-HINT 결과와 유의한 상관성을 보였다. 소 음 하 KS-SL-A의 결과는 경우에 따라 K-HINT 결과와 유의 한 관련성을 보이지 않았으므로 한국어 Matrix 문장을 사용하 여 소음 하 문장인지 검사를 시행하는 것이 공인 타당도 면에 서 보다 적절할 것으로 판단할 수 있다.

본 연구의 제한점은 다음과 같다. 현재 국내에서 상용화되고 있는 변동형 소음 하 문장인지 도구가 부재함으로 고정된 SNR 에서 소음 하 문장인지 검사를 시행하였다. 그러나 실제로 임상 에서 고정된 소음 하에서 문장인지 검사를 시행할 경우 변동형 검사에 비해 검사 소요시간이 오래 걸리고 난이도 조절이 어려 워 난청인에 따라 검사를 시행하지 못할 수 있다는 단점이 있다.

본 연구에서 난청인 대상자에게 KS-SL-A 문장을 제시하였 을 때 검사-재검사 신뢰도가 좋았고 한국어 Matrix 검사 결과 와도 상관성이 있었다. 그러나 KS-SL-A 문장 목록은 원래 조 용한 듣기 상황에서의 평가용으로 개발되었으므로 특정 SNR 에서 소음 하 검사 시행이 불가능할 수 있다. 본 연구에서도 4명 의 난청인이 $0 \mathrm{~dB}$ SNR에서 KS-SL-A 목록을 듣고 인지하는 것 자체가 불가능하였다. 또한 $\mathrm{KS}-\mathrm{SL}-\mathrm{A}$ 은 한정된 문장의 수를 포함하고 있어 여러 번 반복 검사를 할 경우 학습 효과의 우려 가 있다. 따라서 추후 소음 하 검사를 시행할 때 난이도 조절이 용이하고 학습 효과의 가능성이 검사 도구를 선택하는 것이 중 요하겠다. 한국어 Matrix 문장을 제시한 경우 본 연구의 대상자 모두 모든 SNR 조건에서 측정이 가능하였다. Matrix 문장 구조 특징 상 문맥적 힌트가 적어 단어 5 개를 모두 유추하여 답하기 는 어려워 학습 효과의 가능성은 비교적 적은 편이다. 그러나 기 존의 다른 검사 도구에 비해 대상자가 Matrix 문장 내 단어를 모두 듣기 위해 소음 상황에서 보다 집중하여 인지할 가능성이 있으므로 작업기억능력 혹은 집중 능력 등을 함께 확인하는 연 구가 필요할 것이다. Dubno et al.(1984)은 변동형 검사 절차를 이용하여 $50 \%$ 인지하는 데 필요한 $\mathrm{SNR}$ 을 구하였고, 기존에 보 고된 고정된 $\mathrm{SNR}$ 을 사용한 결과에 비해 대상자 편차가 더 적 었다고 하였다. 따라서 추후 연구에서는 변동형 검사 방법을 사 용하였을 때 대상자 간 편차를 최소화할 수 있는지 알아보는 것이 필요하다. 또한 문장의 복합성, 문장 구조 등의 영향에 따 른 결과를 비교하여 보다 효율적이고 신뢰도 있게 소음 하 문 장인지도를 측정하는 절차를 확립해야겠다.
본 연구에서는 난청인을 대상으로 하여 한국어 Matrix 소음 하 문장인지도의 검사-재검사 신뢰도와 공인 타당도 모두 적절 함을 검증하였다. 그러나 검사 도구로서 중요한 요소인 규준, 검 사 점수의 해석 등에 대한 자료를 제시하기에는 부족하다. 특히 본 연구에서는 검사-재검사 신뢰도만을 구하였으므로 향후 연 구에서는 두 검사자가 한 명의 피검자를 대상으로 동일한 검사 를 시행하였을 때 결과가 일치하는지(inter-tester reliability)를 확인하고, $1 \sim 2 \mathrm{~dB}$ 의 차이가 얼마나 검사 결과에 비슷하게 유의 한 변화를 유발하는지 민감도를 측정하는 등의 다양한 신뢰도 검증이 필요하다.

중심 단어 : 소음 하 문장인지·어음청각검사·신호대잡음비· 문장인지도.

\section{Acknowledgments}

이 논문은 2016년 대한민국 교육부와 한국연구재단의 지원을 받 아 수행된 연구입니다(NRF-2016S1A5A8020353). 본 연구에 참 여해 주신 난청인분들께 감사드립니다.

\section{REFERENCES}

Akeroyd, M. A., Arlinger, S., Bentler, R. A., Boothroyd, A., Dillier, N., Dreschler, W. A., et al. (2015). International Collegium of Rehabilitative Audiology (ICRA) recommendations for the construction of multilingual speech tests: ICRA Working Group on Multilingual Speech Tests. International Journal of Audiology, 54(Suppl 2), 17-22.

Bilger, R. C., Nuetzel, J. M., Rabinowitz, W. M., \& Rzeczkowski, C. (1984). Standardization of a test of speech perception in noise. Journal of Speech, Language, and Hearing Research, 27(1), 32-48.

Boothroyd, A., Hanin, L., \& Hnath, T. (1985). A sentence test of speech perception: Reliability, set equivalence, and short term learning. Internal Report RCI10. New York, NY: City University of New York.

Cokely, C. G. \& Humes, L. E. (1992). Reliability of two measures of speech recognition in elderly people. Journal of Speech, Language, and Hearing Research, 35(3), 654-660.

Cox, R. M., Alexander, G. C., \& Gilmore, C. (1987). Development of the Connected Speech Test (CST). Ear and Hearing, 8(5 Suppl), 119S-126S.

Dubno, J. R., Dirks, D. D., \& Morgan, D. E. (1984). Effects of age and mild hearing loss on speech recognition in noise. The Journal of the Acoustical Society of America, 76(1), 87-96.

Fifer, R. C., Jerger, J. F., Berlin, C. I., Tobey, E. A., \& Campbell, J. C. (1983). Development of a dichotic sentence identification test for hearing-impaired adults. Ear and Hearing, 4(6), 300-305.

Jang, H. S., Lee, J. H., Lim, D. H., Lee, K. W., Jeon, A. R., \& Jung, E. J. (2008). Development of Korean standard sentence lists for sentence recognition tests. Audiology, 4(2), 161-177.

Kalikow, D. N., Stevens, K. N., \& Elliott, L. L. (1977). Development of a test of speech intelligibility in noise using sentence materials with controlled word predictability. The Journal of the Acoustical Society of America, 61(5), 1337-1351.

Killion, M. C., Niquette, P. A., Gudmundsen, G. I., Revit, L. J., \& Banerjee, S. (2004). Development of a quick speech-in-noise test for measuring signal-to-noise ratio loss in normal-hearing and hearing-impaired listeners. The Journal of the Acoustical Society of America, 116(4), 23952405.

Kwon, Y. C. \& Park, J. H. (1989). Korean version of Mini-Mental State Examination (MMSE-K). Part I: Development of the test for the elderly. Journal of Korean Neuropsychiatric Association, 28(1), 125-135. 
Moon, S. K., Kim, S. H., Mun, H. A., Jung, H. K., Lee, J. H., Choung, Y. H., et al. (2008). The Korean hearing in noise test. International Journal of Audiology, 47(6), 375-376.

Nilsson, M., Soli, S. D., \& Sullivan, J. A. (1994). Development of the Hearing in Noise Test for the measurement of speech reception thresholds in quiet and in noise. The Journal of the Acoustical Society of America, 95(2), 1085-1099.

Siegenthaler, B. M. (1975). Reliability of the TIP and DIP speech-hearing tests for children. Journal of Communication Disorders, 8(4), 325-333.
Silverman, S. R. \& Hirsh, I. J. (1955). Problems related to the use of speech in clinical audiometry. The Annals of Otology, Rhinology, and Laryngology, 64(4), 1234-1244.

Winkler, A. \& Holube, I. (2016). Test-retest reliability of the Freiburg monosyllabic speech test. $H N O, 64(8), 564-571$.

Yi, D. (2016). Study on the construction and optimization of the Korean matrix sentence materials (unpublished master's thesis). Hallym University of Graduate Studies, Seoul. 